\title{
COMPARISON OF EDGE DETECTION TECHNIQUES FOR HUMAN FEATURE POINTS EXTRACTION
}

\author{
M. A. Massoud ${ }^{1}$, and Shaimaa Kamal ${ }^{2}$ \\ ${ }^{1}$ Doctor, Biomedical Engineering Department, Faculty of Engineering, Minia University, Minia, Egypt, \\ massoud300@yahoo.com. \\ ${ }^{2}$ Teaching Assistant, Electrical and Computer Department, Higher Institute of Engineering and \\ Technology, Minia, Egypt, shklas@gmail.com.
}

\begin{abstract}
Many applications depend on extracting human feature points from 2D images. e.g. noncontact anthropometric measurements, initializing 3D human body shape and recognizing human actions recognition. This paper represented a comparison between various edge detection techniques, which applied on an automated human feature points extraction algorithm from front and side images. Firstly, detecting the body contour. Secondly, Robert, Prewitt, Sobel, Canny and Laplacian of Gaussian (LoG) edge detection techniques are applied to represent the silhouette curve of the human body. Thirdly, Freeman's 8-connected chain codes is applied on the silhouette curve. Finally, a series of feature points are extracted automatically based on some specified rules. Errors and quality comparison techniques, mean square error (MSE), root mean square error (RMSE) and peak signal to noise ratio (PSNR), are used to precisely compare between these different edge detection techniques. The comparison shows that LoG edge detection technique has the least MSE and the most quality.
\end{abstract}

Keywords: Edge dection operators, Freeman's chain code , Feature points extraction, Image processing.

\section{INTRODUCTION}

The popularity of Digital cameras are gain over from being captured conveniently with low cost. Extracting information from 2D images are become more interested especially from the human images. Image based techniques are applied in various studies to detect human body features from 2D images [1-4]. Many body features can be extracted from the body contour shape curve $[5,6]$ Freeman's chain code algorithm is represented the 2D contour in a chain-coded curve [7]. By applying a specific rules on chain code boundary curve, a series of feature points can be extracted.

Automated human feature points extraction algorithm is applied in various fields. It is used in automatic anthropometric measurements, which characterized by accuracy and repetition rather than traditional methods [8]. The efficient creation of the virtual human model is based on precise extraction of human feature points. 3D human model construction from 2D images algorithm is illustrated in $[9,10]$. The body scanner is developed for realizing non-contact 3D measurements that often need to segment the body parts [11]. The identification of human body parts are used in human action recognition [12].

The aim of this article is to present a comparative study between Robert, Sobel, Canny, Prewitt, and LoG techniques to develop an automated body feature points extraction from 2D images algorithm. Reset of the paper is organized as follows: An automated body feature points extraction algorithm is introduced in Section 2. Section 3 introduces basic concepts describing gradient based operators and Laplacian based operator. Experiment results are given in Section 4. Finally a conclusion is given in Section 5.

\section{METHODOLOGY}

The most feature extraction algorithms can be summarized by Fig. 1 . 


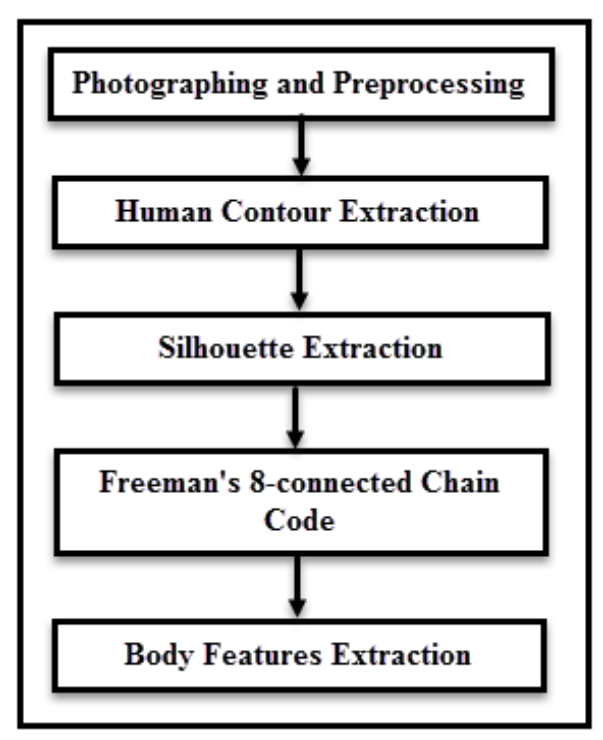

Fig. 1 Block diagram of feature extraction algorithm

\subsection{Photographing and Preprocessing}

The photographing process is illustrated in [13] that determines the camera type, resolution and position. The mentioned algorithm used four images. Two of them are the subject's front and side views and remain images are the background of the front and side views. These images are resized to $309 \times 211$ pixels for front views and 309x84 pixels for side views.

\subsection{Human Contour Extraction}

The human contour is extracted by subtracting the subject image from the background image for both front and side views. Then converted the images from RGB image to a Binary one.

\subsection{Silhouette Extraction}

In this phase a comparison between various edge detection techniques are applied to extract the silhouette curve. These techniques can be classified as either gradient-based edge detection, or Laplacianbased edge detection. The first class includes, Robert operator, Sobel operator, Canny operator and Prewitt operator. The second one includes, Laplacian of Gaussian (LoG) $[14,15]$.

\subsection{Automatic Feature Points Extraction}

Freeman's 8-connected chain code is used to in this phase. This algorithm is used numbers from 0 to 7 to represent 45 degree increment in a counterclockwise direction starting from an initial horizontal vector " 0 " directed to the right $[7,16]$. That is used to represent the silhouette curve as series of connected segments. By applying specific rules listed in [13] on these segments, feature points can be extracted automatically.

\section{GRADIENT BASED AND LAPLACIAN BASE OPERATORS}

\subsection{Gradient Based Operators:}

The gradient based edge detection algorithms determined edges by searching for maximum and minimum values of first derivative of the image. In image processing first derivatives are implemented by gradient magnitude [17].

If $\mathrm{I}(\mathrm{x}, \mathrm{y})$ been the input image, then image gradient is given by,

$$
\nabla I=\hat{x} \frac{\partial \mathrm{I}(\mathrm{x}, \mathrm{y})}{\partial \mathrm{x}}+\hat{y} \frac{\partial \mathrm{I}(\mathrm{x}, \mathrm{y})}{\partial \mathrm{y}}
$$

where $\frac{\partial \mathrm{I}(\mathrm{x}, \mathrm{y})}{\partial \mathrm{x}}$ is the gradient in $\mathrm{x}$ direction and $\frac{\partial \mathrm{I}(\mathrm{x}, \mathrm{y})}{\partial \mathrm{y}}$ is the gradient in $\mathrm{y}$ direction.

The Gradient vector is given by,

$$
\nabla f=\operatorname{grad}(f)=\left[\frac{G x}{G y}\right]
$$

The gradient magnitude is defined as,

$$
|G|=\sqrt{G x^{2}+G y^{2}}
$$

The gradient direction vector is

$$
\theta=\tan ^{-1}\left[\frac{G y}{G x}\right]
$$

The gradient based edge operators are divided either classical operators or canny edge detector [14].

\section{Classical Operators:}

Robert, Sobel, Prewitt are classified as classical operators which are easy to operate but highly sensitive to noise.

\section{Roberts Operator}

It is the primary operator of edge detection algorithms. This operator is based on approximated the image gradient by discrete differentiation. It is the simplest and 
quick algorithm of edge detection. The mask of Roberts operator given by Eq. 5 [18]:

$$
\begin{aligned}
G x=\left[\begin{array}{cc}
-1 & 0 \\
0 & 1
\end{array}\right] & \quad G y \\
= & {\left[\begin{array}{cc}
0 & -1 \\
0 & 1
\end{array}\right] }
\end{aligned}
$$

These two masks can be applied to the image for detecting edges and simply rotated $45^{\circ}$ to each other.

\section{Prewitt Operator}

The Prewitt edge detector can calculate magnitude and orientation of an edge. This gradient based edge detector is estimated in the $3 \times 3$ neighborhood for 8 directions [19]. All the eight convolution masks are calculated. The convolution mask with the largest module is then selected. Equation 6 represents the convolution masks of the Prewitt detector:

$$
\begin{array}{r}
G x=\left[\begin{array}{ccc}
-1 & -1 & -1 \\
0 & 0 & 0 \\
1 & 1 & 1
\end{array}\right] \text { Gy } \\
=\left[\begin{array}{ccc}
-1 & 0 & 1 \\
-1 & 0 & 1 \\
-1 & 0 & 1
\end{array}\right]
\end{array}
$$

\section{Sobel Operator}

Sobel operator [20] is gradient based edge detection algorithms that uses maximum points during the edge detection process. It has two pieces and $3 \times 3$ kernels as shown in Eq.7. These kernels are rotated each other by $90^{\circ}$ and are applied convolution on an image.

$$
\begin{array}{r}
G x=\left[\begin{array}{ccc}
-1 & -2 & -1 \\
0 & 0 & 0 \\
1 & 2 & 1
\end{array}\right] \quad \\
=\left[\begin{array}{ccc}
-1 & 0 & 1 \\
-2 & 0 & 2 \\
-1 & 0 & 1
\end{array}\right]
\end{array}
$$

\section{Canny Edge Detector}

All previous discussed operators have noises as a common defect that caused missing for true edges. To overcome this defect Canny uses Gaussian filter before applying the mask. Gaussian filter reduces the noise as much as possible [15, 21].

There were three objectives based on Canny edge detector algorithm [15, 21]:
1. Low error percentage: all edges could be found. The edges detected close to true edges.

2. Well localization of edges: that represented as the small distance between detected edge and the center of the true edge.

3. Response of single point: the detector returned only one point for each true edge.

Canny edge detection algorithm consists of few steps. Firstly, remove noise which causes errors in the determination of object boundaries. Secondly, two-dimensional derivative (Gx, Gy) of the image intensity are taken. Equation 8 shows a $3 \times 3$ kernel pairs which can be used for canny algorithms. Equation 9 given the formula used to calculate the density of gradient.

$$
\begin{aligned}
& G x=\left[\begin{array}{lll}
-1 & 0 & 1 \\
-2 & 0 & 2 \\
-1 & 0 & 1
\end{array}\right] \quad G y \\
& =\left[\begin{array}{ccc}
1 & 2 & 1 \\
0 & 0 & 0 \\
-1 & -2 & -1
\end{array}\right]
\end{aligned}
$$

$$
\begin{aligned}
& |G| \\
& =|G x| \\
& +|G y|
\end{aligned}
$$

In the third step: the edge regions direction is determined by looking at $\mathrm{x}$ and $\mathrm{y}$ directions. The direction is determined by scanning the pixels at certain angles (often $0^{\circ}, 45^{\circ}, 90^{\circ}$ and $135^{\circ}$ ). After that a non-edge pixels is reduced to level zero. Finally, apply threshold to the image. The threshold value (T) are chosen as a limit- value [22].

\subsection{Laplacian Based Operators}

These operators use the second order partial differential for edge detection. Therefore, it is also called the second order operators. In Laplacian operator we are basically interested in the construction of an isotropic filters. This filter has been a rotation invariant in other words applying the filter and then applying the filter with $90^{\circ}$ again to give the same result. The simplest isotropic derivative is the Laplacian which can be represented in Eq. 10 [14, 22]: 


$$
\begin{aligned}
& \nabla^{2} f \\
& =\frac{\partial^{2} f}{\partial x^{2}} \\
& +\frac{\partial^{2} f}{\partial y^{2}}
\end{aligned}
$$

\section{Marr-Hildreth Operator}

This operator is also called Laplacian of Gaussian (LoG). The authors of this method have suggested that the edge detection operator should has two main features:

1. The operator should be applied the first or second derivative at any point.

2. The operator should be applied at any desired scale.

The efficient operator that can be contained those features is the filter $\nabla^{2} G$ where $\nabla^{2}$ is the Laplacian operator and $G$ is a 2-D Gaussian filter function, i.e.,

$G(x, y)$

$=-e^{\frac{x^{2}+y^{2}}{2 o^{2}}}$

where ó is the standard deviation. Now $\nabla^{2} G$ is given by:

$\nabla^{2} G$

$=-\left[\frac{x^{2}+y^{2}-\dot{o}^{2}}{\dot{o}^{4}}\right] e^{-\frac{x^{2}+y^{2}}{2 \dot{o}^{2}}}$

\section{EXPERIAMENTAL RESULTS}

MATLAB 2017 Image Processing Tool box is used to compare between the five techniques. The first comparison is between the original image and the silhouette curve that can be extracted after applied the edge detection techniques as shown in Fig. 2 and Fig.3. The original image has resolution of $309 \times 211$ pixels for front view and 309x84 pixels for side view.
There are many parameters which can be used to compare all mentioned edge detection operators. The following methods are used for this purpose.

\section{Mean Square Error (MSE)}

MSE is used to evaluate the performance of predictor. It is defined as:

$$
=\frac{M S E}{M x N}
$$

where $f 1$ and $f 2$ are two $(\mathrm{M} \times \mathrm{N})$ image matrices.

\section{Root Mean Square Error (RMSE)}

It is defined as:

$$
=\sqrt{M S E}
$$

$$
R M S
$$

\section{Peak signal to noise ratio (PSNR)}

This criteria represents the ratio between maximum power of a signal and the power of noise. The image reconstruction ability is increased by the increasing of PSNR value. It is defined by the following equation.

$$
\begin{aligned}
& P S N R \\
& =\left(10 \times \log \left(\text { peakval }^{2}\right.\right. \\
& / M S E))
\end{aligned}
$$

where peakval is the maximum pixel value of an image.

The comparison between all the techniques is applied by using Matlab software on JPG images with a resolution of $309 \times 211$ pixels and 309x84 pixels for front and side views respectively. The comparison of MSE, RMSE and PSNR for all illustrated operators and original image are given in Table 1 and Table 2.

Table 1. Comparison values for front view

\begin{tabular}{|c|c|c|c|}
\hline & MSE & RMSE & PSNR \\
\hline Robert & 0.2660 & 0.5158 & 5.7512 \\
\hline Prewitt & 0.2646 & 0.5144 & 5.77740 \\
\hline Sobel & 0.2650 & 0.5148 & 5.7672 \\
\hline Canny & 0.2641 & 0.5139 & 5.7818 \\
\hline LoG & 0.2439 & 0.4939 & 6.1276 \\
\hline
\end{tabular}


Table 2. Comparison values for side view

\begin{tabular}{|c|c|c|c|}
\hline & MSE & RMSE & PSNR \\
\hline Robert & 0.4972 & 0.7051 & 3.0345 \\
\hline Prewitt & 0.4975 & 0.7053 & 3.0324 \\
\hline Sobel & 0.4973 & 0.7052 & 3.0341 \\
\hline Canny & 0.4970 & 0.7050 & 3.0365 \\
\hline LoG & 0.4671 & 0.6834 & 3.3059 \\
\hline
\end{tabular}

Table 1 and Table 2 show that LoG edge detection operator has the least MES value and the largest value of PSNR, i.e., it is the best one to represent the original image and it is recommended for use.

The second comparison is shows the difference between the feature points extraction, using the algorithm illustrated in [13] that used canny edge detection technique and the same algorithm when used LoG edge detection technique. Fig. 4 and Fig. 5 show the feature points extraction after applied the two techniques on the front and side views respectively.
By applying the LoG edge detection technique, there are 121 feature points are extracted from the front and side views 82 from the front view and 39 from the side view. However only 115 feature points are taken 80 from the front view and 35 from the side view. These points are neglecting because of repeating closely to another one. By comparing the extracted points with another one represented in [13], there are 14 additional feature points, 10 points in the front view and 5 points in the side view. 
A: Original

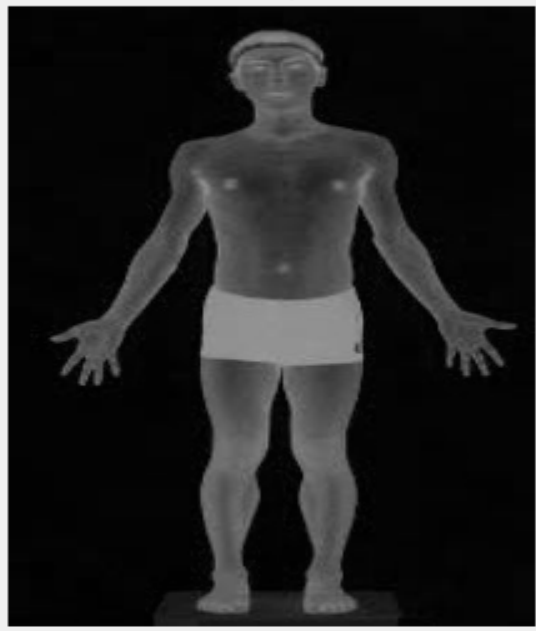

D: Roberts

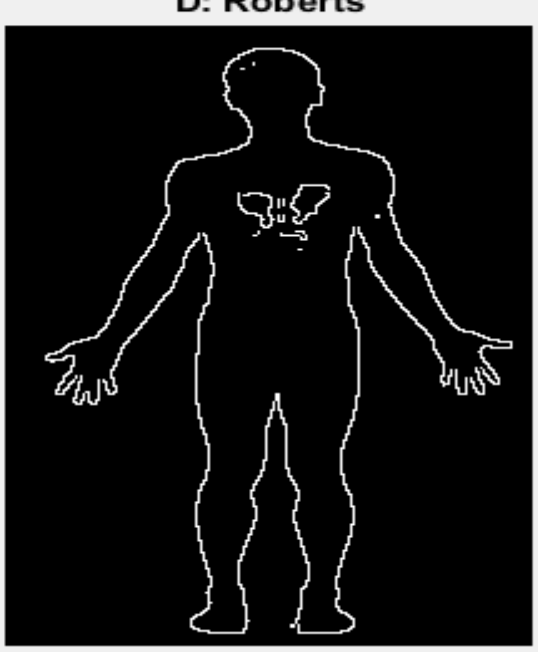

Fig.2. Comparison of all illustrated edge detection operators for front view
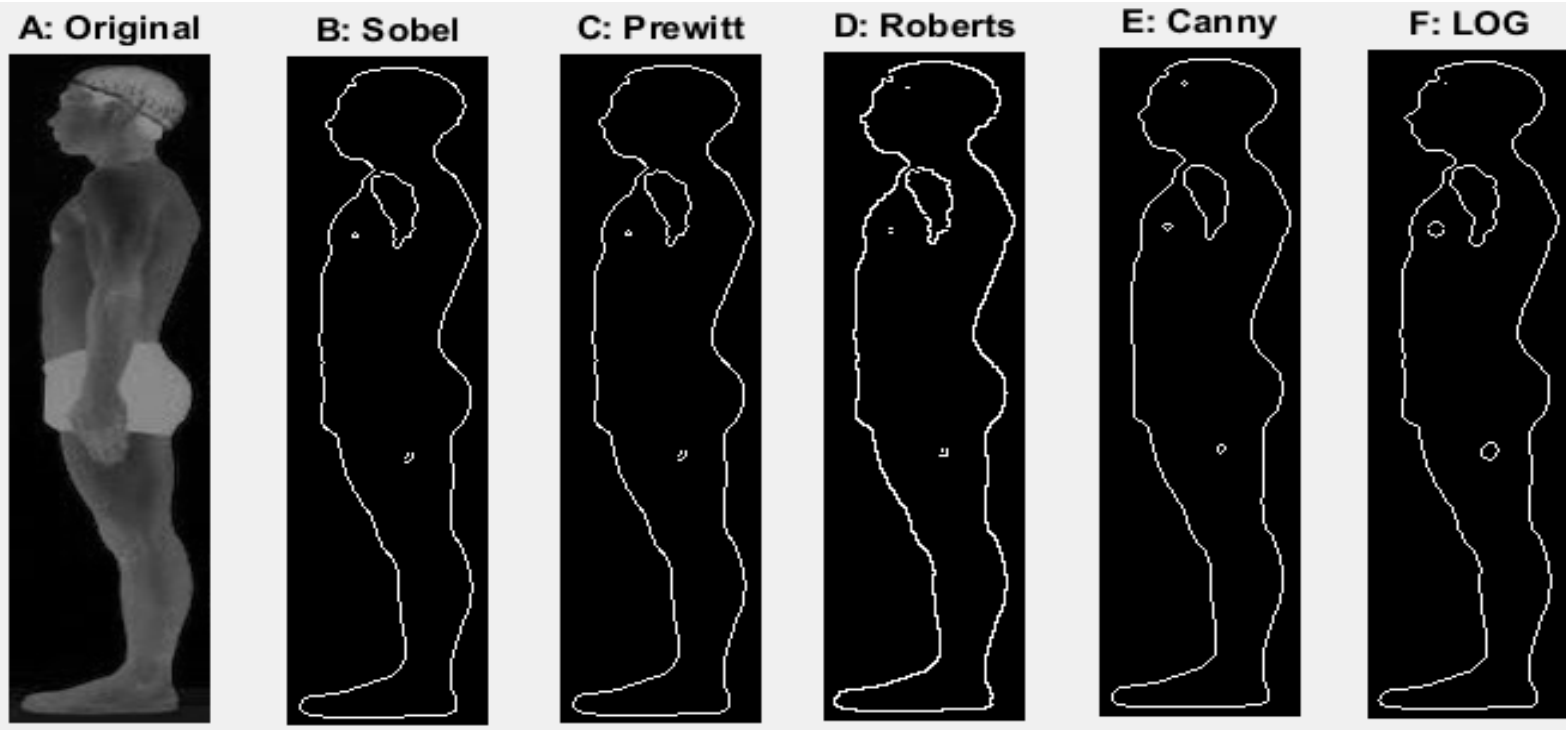

Fig.3. Comparison of all illustrated edge detection operators for side view 


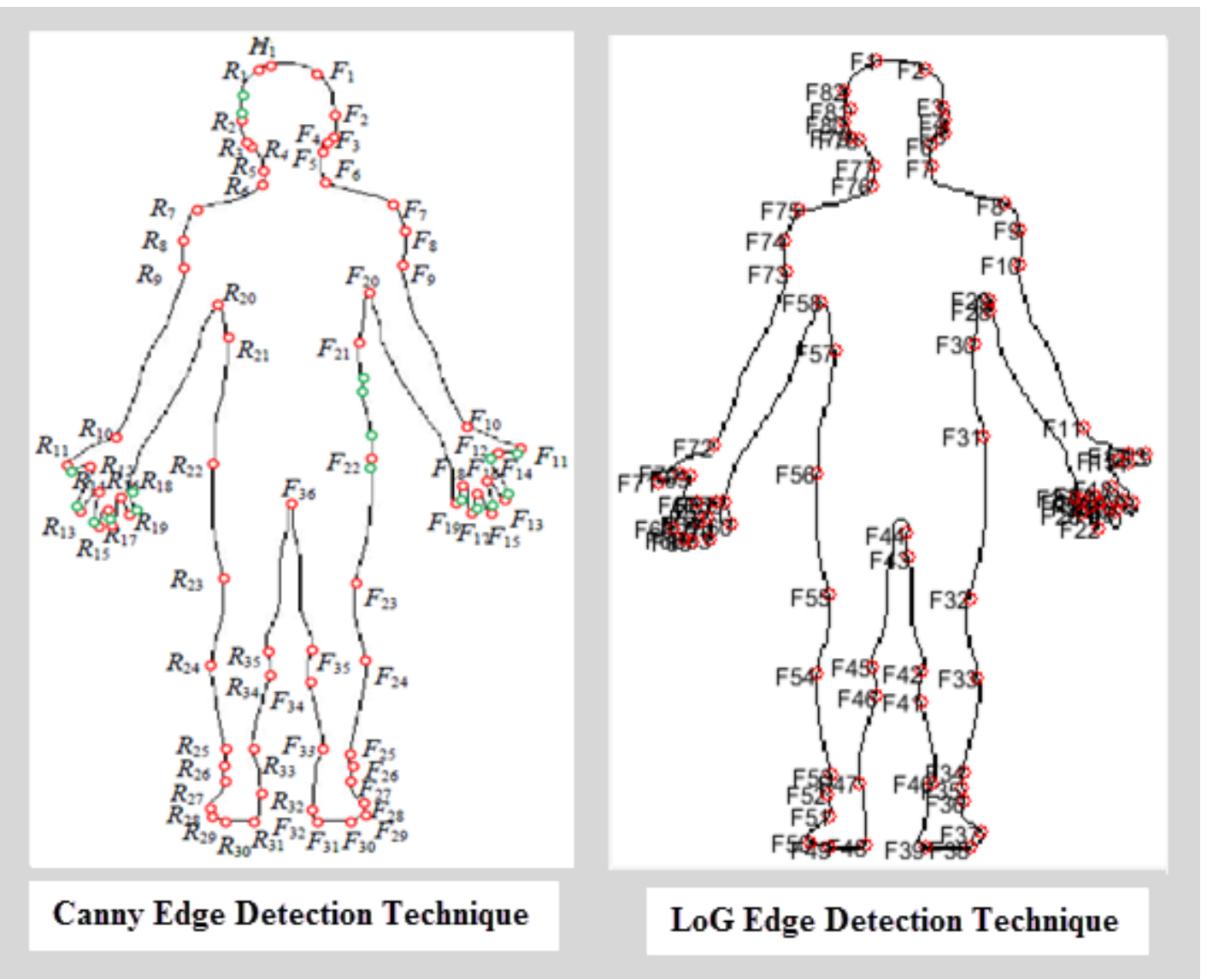

Fig.4. Feature points extraction from the front view

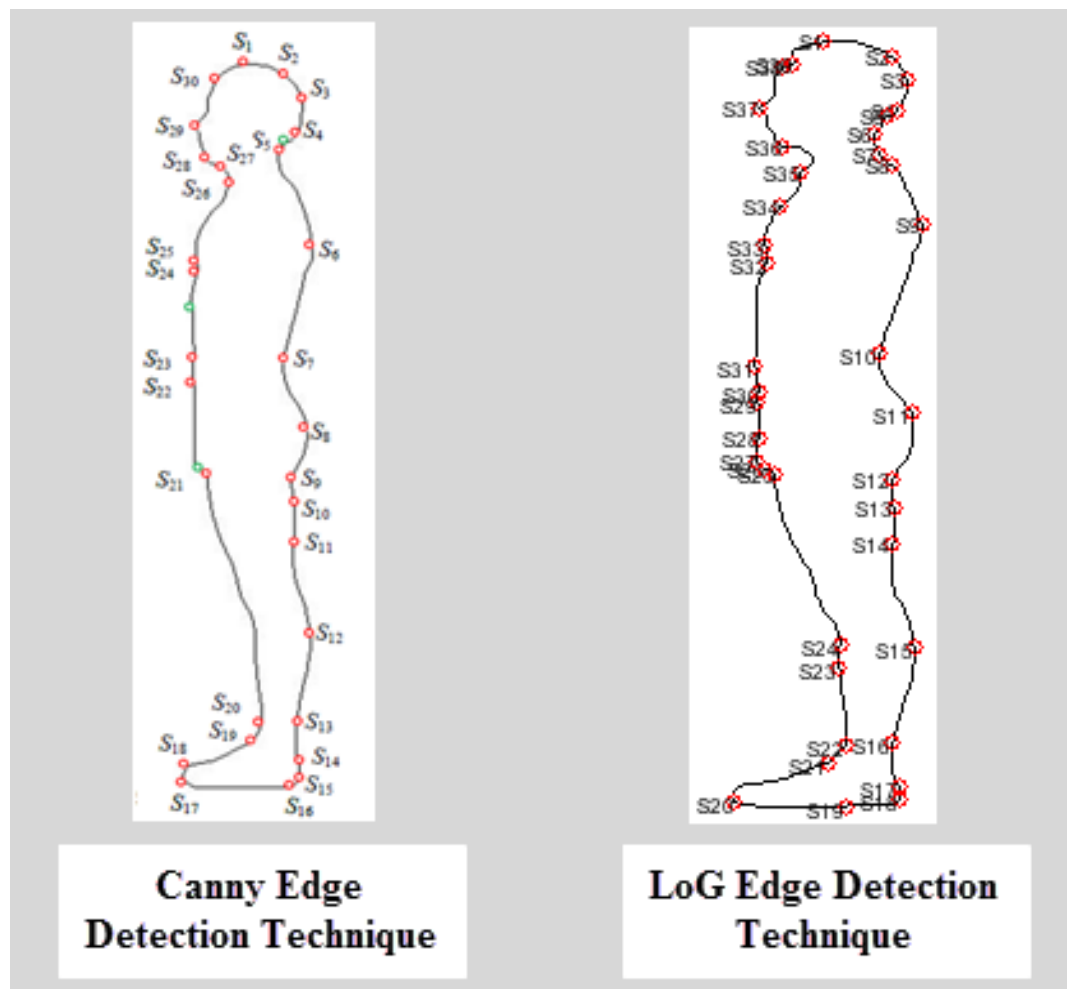

Fig.5. Feature points extraction from the side view

\section{CONCLUSION}

This paper addressed a comparative study between the popular detection algorithms. All the considered edge detection techniques are compared with the original image, 
using three different criteria; MSE, RMSE and PSNR. These results illustrated that LoG edge detection operator yielded the least of error and the most quality. Therefore replacing Canny edge detection technique by LoG edge detection technique, more feature points were extracted precisely. 115 feature points (80 from the front view and 35 from the side view) instead of 101 feature points (71 from the front view and 30 from the side view).

\section{REFERENCES}

[1] Cordier, F., Lee, W., Seo, H., MagnenatThalmann, N.," From 2D photos of yourself to virtual try-on dress on the web," People and computers XV Interaction without frontiers: Joint proceedings of HCI 2001 and IHM 2001. Springer Publisher, 2001.

[2] Hilton, A., Beresford, D., Gentils, T., Smith, R., Sun, W., Illingworth, J., "Whole-body modelling of people from multiview images to populate virtual worlds," The Visual Computer, Vol. 16, No. 7, pp. 411-436, 2000.

[3] Lee, W., Gu, J., Magnenat-Thalmann, N., "Generating animatable 3D virtual humans from photographs," Eurographics, Computer Graphics Forum, Vol.19, No. 3, pp. 1-10, 2000.

[4] Seo, H., Yeo, Y., Wohn, K., "3D body reconstruction from photos based on range scan," Lecture Notes in Computer Science, Vol. 3942, pp. 849-860, 2006.

[5] Wang, C. C. L., Wang, Y., Chang, T. K. K., Yuen, M. M. F., "Virtual human modeling from photographs for garment industry," Computer-Aided Design, Vol. 35, No. 6, pp. 577-589, 2003.

[6] Arlow, J., Lawrence, K., \& Treleaven, P., "Body XML draft specification," e-T Cluster IST-2000-26084, Bodymetrics and UCL, UK, 2001.

[7] Freeman, H., Davis, L. S., "A cornerfinding algorithm for chain-coded curves," IEEE Transactions on Computers, Vol. 26, No. 3, pp. 297-303, 1977.
[8] P. Meunier and S. Yin, "Performance of a 2D image-based anthropometric measurement and clothing sizing system," Applied Ergonomics, Vol. 31, No. 5, pp. 445-451, 2000.

[9] Y.L. Lin and M.J. Wang, "Constructing 3D Human Model from 2D images," Int. Conf. on Industrial Engineering and Engineering Management, Xiamen, pp.1902-1906, 2010.

[10] Y.L. Lin and M.J. Wang, "Constructing 3D human model from front and side images," Expert Systems with Applications, Vol. 39, No. 5, pp. 5012-5018, 2012.

[11] J.M. Lu and M.J. Wang, "Automated data collection using 3D whole body scanner," Expert Systems with Applica-tions, Vol. 35, No. 1-2, pp. 407-414, 2008.

[12] A. Ali and J.K. Aggarwal, "Segmentation and recognition of continuous human activity," Proc. IEEE Workshop on Detection \& Recog. of Events in Video, Vancouver, BC, pp. 28-35, 2001.

[13] Lingyan Jiang, Jian Yao, Baopu Li, Fei Fang, Qi Zhang, Max Q.-H. Meng, "Automatic body feture extraction from front and side images," Journal of Software Engineering and Applications, Vol. 5, pp. 94-100, 2012.

[14] Rashmi, Mukesh Kumar, Rohini Saxena, "Algorithm and Technique on Various Edge Detection: A Survey," An International Jornal of Signal\& Image Processing, Vol. 4, No. 3, pp. 65-75, 2013.

[15] Simranjit Singh, Rakesh Singh, " Comparison of Various Edge Detection Techniques," $2^{\text {nd }}$ International Conference on Computing for Sustainable Global Development (INDIACom), IEEE, New Delhi, India, p.p 393-396, 2015.

[16] H. Freeman, "On the encoding of arbitrary geometric con-figuration," IRE Transactions on Electronics Computers, Vol. EC-10, No. 2, pp. 264-268, 1961.

[17] R. C. Gonzalez, R. E. Woods, "Digital Image Processing," Upper Saddle River, NJ: Prentice-Hall, pp. 572-585, 2001.

[18] R. C. Gonzalez, R. E. Woods, "Digital Image Processing," 2nd ed.Prentice Hall, 2002. 
[19] Prewitt, J., "Object Enhancement and Extraction," Picture Processing and

[20] Sobel, I., "Camera Models and Perception," Ph.D. thesis, Standford University, CA, 1970.

[21] J. F. Canny, "A computational approach to edge detection," IEEE Trans. Pattern Anal. Machine Intell, Vol. PAMI-8, No. 6, pp. 679-697, 1986.

[22] Saban Ozturk, Bayram Akdemir, "Comparison of Edge Detection Algoriths for Texure Analysis on Glass Production,"
Psychopictorics, NY, Academic Pres, 1970.

Proccdia- Social and Behavioral Science, Vol. 195, pp. 2675-2682, 2015.

[23] J. Sophia, J. Maria Divyalnfanta, "A Study on Edge Detection Methods," National Conference on Advances in Computer Science and Application (ACSA), pp. 994999, 2016. 


\section{مقارنة بين تقنيات كثف الحواف لاستخراج النقاط المميزة للجسم البشري محمد أحمد مسعود، شيماء كمال}

الملخص

تنتخم النقاط الميزة للجسم البشري فى العيد من النطيقات منل القياسات الجسية والتعرف علي حركة الجسم البشري واسنتاج الثنكل ثلاثي الأبعاد. يقدم هذا البحث مقارنة بين العيد من النقيات المستخمة في كثف الحواف مثل Robert, Prewitt, Sobel, Canny and Laplacian of Gaussian (LoG)) الأمامية والجانيية. حيث يقوم الخوارزم المقدم بتحليد حود الجسم البثري وتطبيق ثقنيات كثف الحواف لإيجاد الثنكل الظلي للجسم البشري ثم يتم تطييق Freeman's 8-connected chain code عليه وخيراً ينت إستخراج مجموعة من النقاط المميزة للجسم البشري آلياً معتدة على mean squre error (MSE), root mean square error طبيق بعض القواعد المحدة. نستخم نقنيات مقارنة نسبة الخطأ والكفاءة منل للكقارنة بين تقنيات كثف الحواف المختلفة. أوضحت المقارنة أن تقنية LOG (RMSE), and peak to noise ratio (PSNR) الحواف لها أقل نسبة خطا وأعلى كفاءة. 